\title{
A recurrence of Kcot after 4 years: A case report
}

\author{
Amod Patankar ${ }^{1}$, Arun Dugal $^{2}$, Saurabh Khandelwal ${ }^{3}$, Apoorva Iyengar $^{4}$, \\ Swapna Patankar ${ }^{5}$ \\ ${ }_{1,2,3,4}$ (Department Of Oral And Maxillofacial Surgery, Bharati Vidyapeeth Deemed University Dental College \\ And Hospital, Pune Maharashtra, India) \\ ${ }^{5}$ (Department Of Oral And Maxillofacial Pathology, Bharati Vidyapeeth Deemed University Dental College And \\ Hospital, Pune Maharashtra, India)
}

\begin{abstract}
Odontogenic keratocyst is characterized by a large squamous keratinization of its border, an aggressive growth [4] and a high recurrent rate. It has recentlybeendesignated by the World Health Organization as a Keratocystic Odontogenic Tumour (KCOT)[6]. The diagnosis can beconfirmed by the histopathologic examination only. The treatment modalities used are decompression, marsupialization, enucleation and curettage and resection. However, the most appropriate treatment protocol still remains a controversy. The follow up is characterized by a high rate of recurrence. And, therefore, to reduce the chances of recurrences, along with the surgical modalities like enucleation, chemical and thermal cauterization may be used to deal with the problem of satellite microcysts. We present a case of OKC with recurrence in a 26 year old male.
\end{abstract}

Keywords: Keraocystic odontogenic tumour, Recurrence, Enucleation, Chemical cauterization, Carnoys solution

\section{Introduction}

First described by Philipsen in 1956[1], the odontogenic keratocyst is characterized by a large squamous keratinization of its border. It shows an aggressive growth [4] and a high rate of recurrence of 13$30 \%[5]$. It is now designated by the World Health Organization as a Keratocystic Odontogenic Tumour (KCOT)[6]. Clinically, KCOT is manifested by an asymptomatic growth. Radiographically, it appears as a welldefined uni-locular or multilocular osteolytic lesion[5]. The diagnostic approach is based on a combined analysis of the medical history, the clinical appearance and the radiographic appearance and can be confirmed by the histopathology report only[5]. There are various treatment modalitiesfor this type of lesion and the follow up is characterized by a high rate of recurrence. Here we present a case of multicysticKCOTs with recurrence in a 26 year old male treated by with the conservative approach -marsupialisation followed by enucleation.

\section{Case Report}

A 26 year old male presented to the department of oral and maxillofacial surgery with a complaint of swelling and slight discomfort in the lower left side of his face (Fig. 1). His past medical history was unremarkable.

He was a known case of multicystic Odontogenic keratocysts( Fig.2,3) operated byMarsupializaion of the cysts in the right and left maxillaryanterior region and left mandibular posterior region with extraction of teeth nos. 33, 37 and 38. Following surgery, fouryears later the swelling re-appeared. He presentedwith a complaint of swelling with slight discomfort in the mandibular left posterior region. There was no complaint of paresthesia or pain in relation to the region of the swelling.

Intraorally, on clinical examination, a fluctuant swelling in the mandibular left posterior region extending to the anterior region and to the right premolar with obliteration of the buccal vestibule was observed. Overlying mucosa was normal (Fig. 4). On aspiration, Viscoid straw coloured fluid was obtained.

Extraoral examination revealed a diffuse, firm to bony hard, non-fluctuant swelling seen involving the left mandible and extending to below the lower border with no draining sinus (Fig. 5). On palpation, a soft swelling in the anterior region but bony hard on the posterior buccal aspect, with expansion of the buccal and lingual plates, extending from anterior mandibular region to the ascending ramus of mandible on the left sidewas observed.

An OPG and CBCT were the radiological investigations advised. The OPG showed a well corticated radiolucent lesion involving the left mandible extending from the periapical region of 45 through the mandiblecrossing the midline to involve the ramus of the left side and extending to the sigmoid notch. The lower border of the mandible was intact. Missing teeth were 33, 37 and 38. The root canal treated teeth were 41, 31, 32, 34, 35 and 36. (Fig. 6) 
The CBCT (Fig. 7) revealed loss of buccal cortication, root resorption in relation to 36 and the mandibular canal displaced inferiorly(Fig. 8). Also lingual perforation was observed.

The patient was then advised enucleation and curettage and chemical cauterisation with the use of Carnoy's solution.

\subsection{Procedure Under General Anaesthesia}

The incision was taken slightly below the mucogingival junction and above the vestibule so that bone covering the teeth and the gingiva were preserved instead of exposing it with a crevicular incision. The cyst was enucleated in parts gradually from the anterior region onwards to the posterior ramus region of the left mandible.Perforation of $0.5 \mathrm{~cm}$ of bone was also seen in the lingual region posteriorly. The lingual bone and inferior border post-enucleation werethin and therefore it was decided that a peripheral ostectomy would not be carried out. The specimens were sent for histopathological examination. It was found that the specimen obtained from the posterior mandibular ramus area was firm and solid suggesting a possible tumour transformation of the cystic lesion while the specimen from the anterior region was more cystic with straw coloured fluid.

Once enucleation was done completely, irrigation of the defect was done with $\mathrm{H} 2 \mathrm{O} 2$, Povidone iodine and NS. Carnoy's solution was mixed freshly. A gauze soaked with Carnoy's solution was then applied onto the bony walls and the solution was allowed to stay for 3-5 mins [7, 25]. This was repeated two to three times. Post application, chemical cauterization was observed. Following which, excess solution was removed and irrigation repeated. Povidone iodine soaked roller gauze pieces were then packed in the cavity and stay sutures were given to hold the gauze in situ leaving the cavity open for changing of the gauze drain and secondary healing. The histopathological report results showed that the lesion was a Keratocystic Odontogenic Tumour.

Subsequently, post- discharge a plate was given to allow for oral intake of food.

\section{Discussion}

The lesion, now called the Keratocystic Odontogenic Tumour (KCOT)[6] was first described by Philipsenin 1956[1] under the name Odontogenic Keratocyst. It was, however, not widely recognized as a separate entity until articles by Browne in 1970 and 1971[2,3] which clearly delineated the clinical and histological features of the lesion, coupled with its high recurrence rate and simple enucleation as a treatment modality.Studies have shown that OKCs had a recurrence rate of 3-62 \% [8,9]. This recurrence can occur even years after initial treatment. Therefore, a long term follow up is essential.

Following the confirmation of the accuracy of histological diagnosis and of the high recurrence rate of these lesions with simple treatment, there was a division of philosophies on their management.

They were extreme opinions regarding how the lesion had to be dealt with from a simple curettage as suggested by Gordan Hardman[10] to an 'en-bloc' or segmental resection depending on the size as recommended by Paul Bramley[11]. Stoelinga and others are of the opinion that these lesions can arise from down growth from the oral epithelium and that, therefore, the overlying oral epithelium should be excised along with the lesion[12].

During enucleation parts of KCOTs lining are left in place, which may be expected for lesions with thin and vulnerable walls. It was shown that recurrences are more common in KCOTs which are removed in several pieces, but also in multilocular lesions and lesions which had perforated the cortical bone.

Three possible mechanisms responsible for KCOTs recurrences were proposed[13]:

O Incomplete removal of the lesions during the surgery,

O Formation of satellite microcysts within the cystic lining

O Development of new lesions from epithelial off-shoots of the basal layer of the oral epithelium.

It was, however, felt that additional treatment was required to remove any small daughter cysts or remnants beyond the visible cyst lining. In an effort to identify this middle course, treatment consisting of techniques ranging from enucleation plus cryosurgery, utilized extensively over the last 30 years $[14,15]$ to enucleation plus Carnoy's Solution[8, 16], enucleation with peripheral ostectomy[17], and more recently marsupialization and decompression[18-21], with various combinations. The chemical and thermal cauterization agents included use of Liquid Nitrogen or Carnoy's solution to tackle the problem of retention of the daughter cysts.

Pogrel et al first published an article on the use of enucleation coupled with liquid nitrogen in 1993[14] and at that time reported a recurrence rate of around $11.5 \%$, which was less than the recurrence rates of 20-60\% that were being reported for simple enucleation. The problem with the technique, however, has been access to the equipment, which is being used less and less in other medical specialties, so hospitals often do not have access to it. Also, if one is not meticulous in protecting the soft tissues, there will be necrosis of the soft tissues leading to wound breakdown and a prolonged recovery, and at least partial loss of any bone graft that has been used. 
Carnoy's solution was first used as a medicament in surgery by Cutler and Zollinger in 1933[22]. It was shown to eradicate epithelial rests from the cyst wall.Its average depth of penetration is said to be $1.54 \mathrm{~mm}$ after 5 mins of application[7]. It contains Ferric chloride, Glacial acetic acid, Chloroform and Absolute alcohol. Carnoy's solution has some disadvantages in that it is not easily obtainable and some of its contents may have side effects. Chloroform may be carcinogenic as considered by theCalifornia Occupational Health and Safety Administration and was banned in 1992 by the US Food and DrugAdministration (FDA)[26] and the handling of glacial acetic acid requires a high volume fume cupboard. Some practitioners have been removing the chloroform from Carnoy's solution, but this new formulation has not been tested and has not been shown to be effective.Treatment of the cyst with carnoy's solution may damage the bone and nerve tissue. However, Blanas et al [25] state thatapplication of carnoy's solution to cyst cavityfor 3 mins after enucleation should notdamage the inferior alveolar nerve.

However, several studies showed that usage of Carnoy's solution following enucleation significantly reduces number of recurrences compared to enucleation alone [8, 23, 24].Developing this method, Stoelinga and co-workers proposed a protocol of treatment consisting of enucleation, followed by application of Carnoy's solution and excision of soft tissues in contact with cystic lining[12].

\section{Conclusion}

Since the patient reported back with a recurrence, a different line of treatment had to be chosen apart from marsupialization followed byenucleation. There were two options, an aggressive anda conservative approach. An aggressive approach of resection was not considered, taking into account the patient's age. Therefore, enucleation with the use of an adjunct like Carnoy's solution was decided as a suitable treatment modality in this case. important.

Also, after surgical treatment, periodic post-treatment clinical and radiographic examinations are

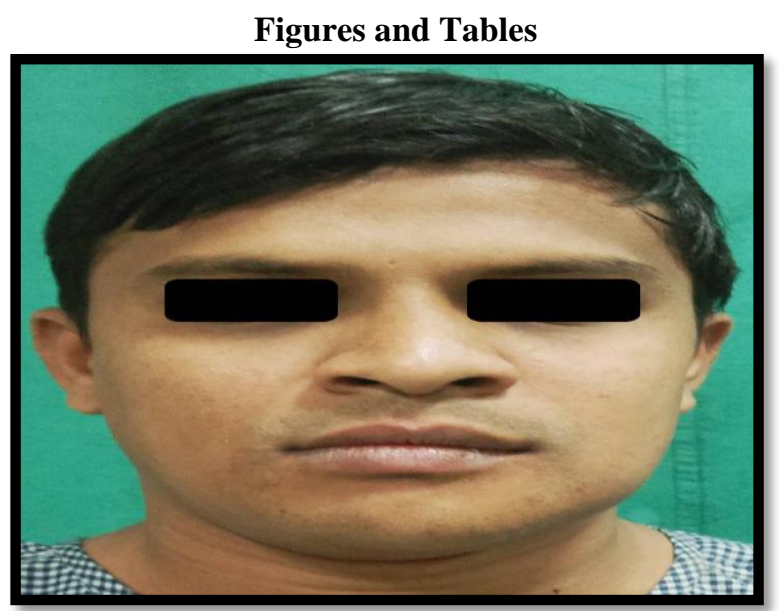

Fig. 1: 26 year old male with a complaint of swelling in relation to the lower left side of the face.

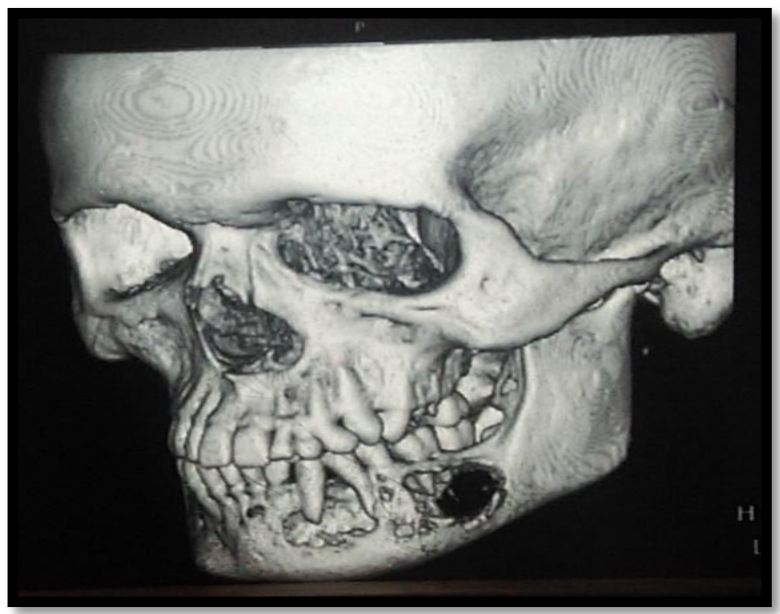

Fig. 2: Previous CT scan done prior to marsupialization of the Odontogenic keratocyst (First surgery) 


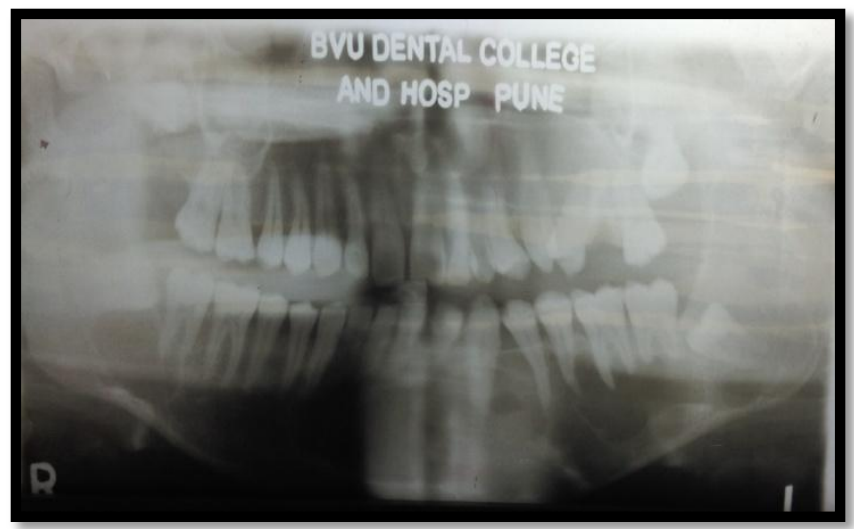

Fig. 3: Previous OPG done prior to marsupialization of the keratocyst (First surgery)

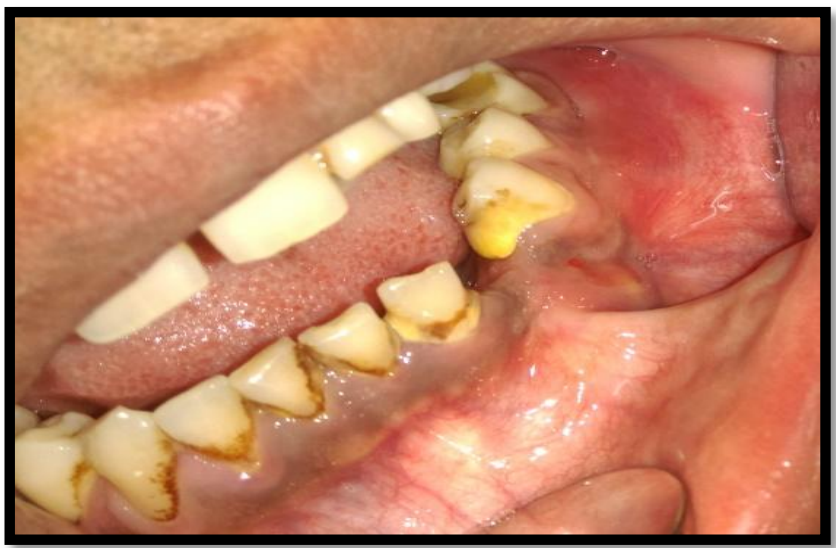

Fig. 4: Overlying mucosa appears normal with slight erythema and no draining sinus

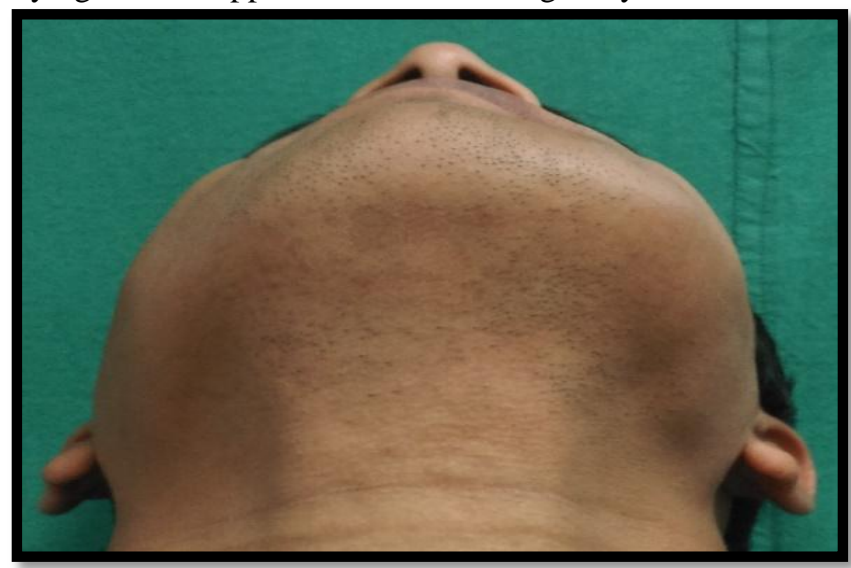

Fig. 5: Extraoral examination reveals swelling in relation to the left mandible with cortical expansion

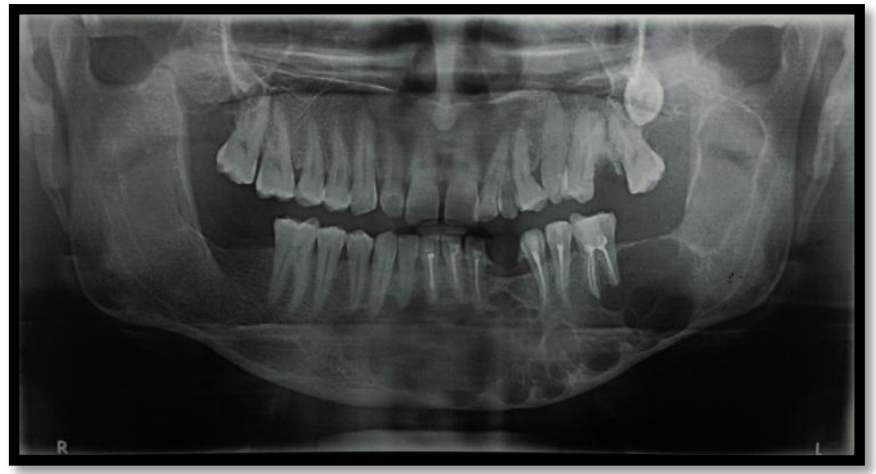

Fig. 6: Recent OPG prior to Enucleation of the Odontogenic keratocyst reveals the extent of the lesion 


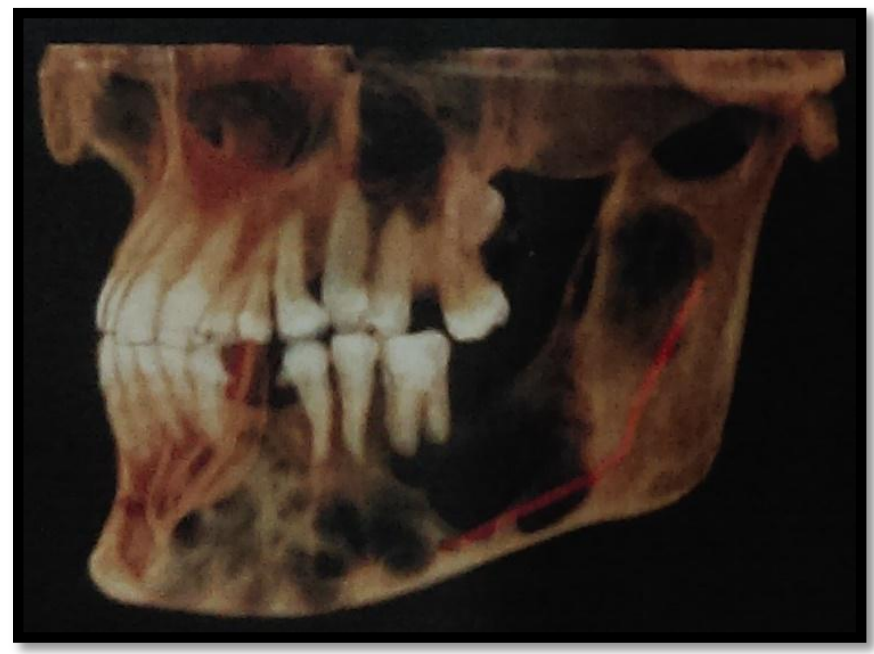

Fig. 7: Recent CBCT prior to Enucleation of the Odontogenic keratocyst

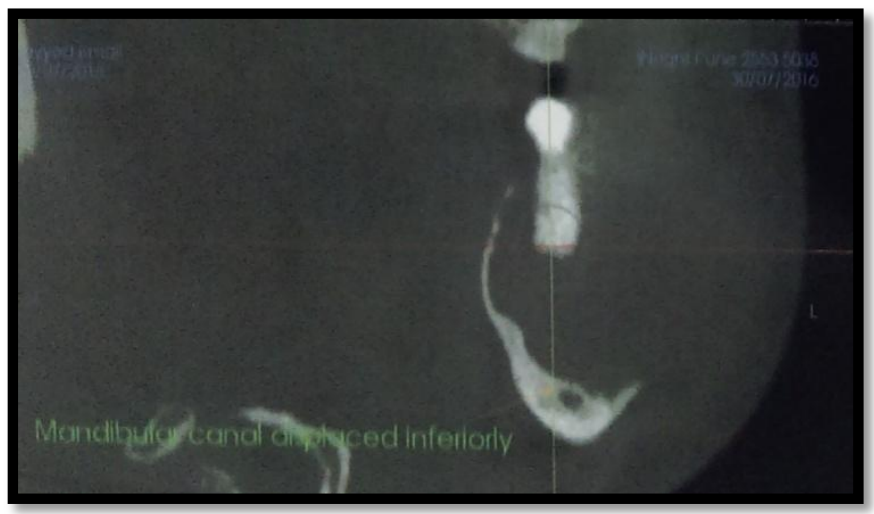

Fig. 8: CBCT showing displacement of the mandibular canal inferiorly

\section{References}

[1]. PhilipsenHP. Om keratocyster (kolesteatomer) ikæberne. Tandlægebladet 1956;60:963-81. Quoted from M.A. Pogrel: The keratocystic odontogenic tumour (KCOT) —an odyssey. Int. J. Oral Maxillofac. Surg. 2015; 44: 1565-1568.

[2]. Browne RM. The odontogenic keratocyst. Clinical aspects. Br Dent J 1970;128:225-31.

[3]. Browne RM. The odontogenic keratocyst Histological features and their correlation with clinical behaviour. Br Dent J 1971;131:249-59.

[4]. Shear M. The aggressive nature of the odontogenic keratocyst: is it a benign cystic neoplasm? Part 1. Clinical and early experimental evidence of aggressive behaviour. Oral Oncol. 2002;38(3):219-226. A.

[5]. Shafer, Hine, Levy. Cysts and Tumours of Odontogenic origin. Oral Pathology. $6^{\text {th }}$ edition, Elsevier, 2009, p254-308.

[6]. Reichart PA, Philipsen HP, Sciubba JJ. The new classification of head and neck tumours (WHO) - any changes? Oral Oncol 2006;42: 757-8.

[7]. Voorsmit RA. The incredible keratocyst: a new approach to treatment. DtschZahnarztl Z 1985;40: 641-4.

[8]. Voorsmit RA, Stoelinga PJ, van Haelst UJ. The management of keratocysts. J Maxillofac Surg. 1981;9(4):228-236.

[9]. Pindborg JJ, Hansen J. Studies on odontogenic cyst epithelium. 2. clinical and roentgenologic aspects of odontogenic keratocysts. ActaPatholMicrobiol Scand. 1963; 58: 283-294.

[10]. M.A. Pogrel: The keratocystic odontogenic tumour (KCOT)—an odyssey. Int. J. Oral Maxillofac. Surg. 2015; 44: 1565-1568.

[11]. Bramley P, The odontogenic keratocyst—an approach to treatment. Int J Oral Surg 1974;3: 337-41.

[12]. Stoelinga PJ. (B) Excision of the overlying attached mucosa, in conjuction with cyst enucleation and treatment of the bony defect with carnoy solution. Oral Maxillofacial SurgClin N Am. 2003; 15(3):407-414.

[13]. Forssell K, Forssell H, Kahnberg KE. Recurrence of keratocysts. A long-term followup study. Int J Oral Maxillofac Surg. 1988;17(1):25-28

[14]. Pogrel MA. The use of liquid nitrogen cryotherapy in the management of locally aggressive bone lesions. J Oral MaxillofacSurg 1993;51:269-73.

[15]. Schmidt BL, Pogrel MA. The use of enucleation and liquid nitrogen cryotherapy in the management of odontogenic keratocysts. J Oral MaxillofacSurg 2001;59:720-5.

[16]. Stoelinga PJ. Long-term follow-up on keratocysts treated according to a defined protocol. Int J Oral MaxillofacSurg 2001;30:14-25.

[17]. Irvine GH, Bowerman JE. Mandibular keratocysts: surgical management. Br J Oral MaxillofacSurg 1985;23:204-9.

[18]. Pogrel MA. Decompression and marsupialization as a treatment for the odontogenic keratocyst. Oral MaxillofacSurgClin North Am $2003 ; 15: 415-27$.

[19]. Pogrel MA, Jordan RC. Marsupialization as a definitive treatment for the odontogenic keratocyst. J Oral MaxillofacSurg 2004;62:651-5.

[20]. Pogrel MA. Treatment of keratocysts: the case for decompression and marsupialization. J Oral MaxillofacSurg 2005;63:1667-73. 
[21]. Pogrel MA. Decompression and marsupialization as definitive treatment for keratocysts- a partial retraction. J Oral MaxillofacSurg 2007;65:362-3.

[22]. Cutler EC, Zollinger R: The use of sclerosing solutions in the treatment of cysts and fistulae. Am J Surg 19:411, 1933.

[23]. Nigel R. Johnson et al: Management and recurrence of keratocystic odontogenic tumor: a systematic review. Oral Surg Oral Med Oral Pathol Oral Radiol 2013;116:e271-e276.

[24]. Zhao YF, Wei JX, Wang SP. Treatment of odontogenic keratocysts: a follow-up of 255 Chinese patients. Oral Surg Oral Med Oral Pathol Oral RadiolEndod. 2002;94(2): 151-156.

[25]. Blanas N, Freund B, Schwartz M, Furst IM. Systematic review of the treatment and prognosis of the odontogenic keratocyst. Oral Surg Oral Med Oral Pathol Oral RadiolEndod; 90(5): 553 8(2000)

[26]. US Food and Drug Administration. Section 460.200, in FDA Compliance Policy Guides. Washington, DC, Food and DrugAdministration, 1992, p 219. 